\title{
Research
}

\section{Barriers, facilitators, and survival strategies for GPs seeking treatment for distress:}

a qualitative study

\begin{abstract}
\section{Background}

GPs are under increasing pressure due to a lack of resources, a diminishing workforce, and rising patient demand. As a result, they may feel stressed, burnt out, anxious, or depressed.

\section{Aim}

To establish what might help or hinder GPs experiencing mental distress as they consider seeking help for their symptoms, and to explore potential survival strategies.

\section{Design and setting}

The authors recruited 47 GP participants via e-mails to doctors attending a specialist service, adverts to local medical committees (LMCs) nationally and in GP publications, social media, and snowballing. Participants selfidentified as either currently living with mental distress, returning to work following treatment, off sick or retired early as a result of mental distress, or without experience of mental distress. Interviews were conducted face to face or over the telephone.
\end{abstract}

\section{Method}

Transcripts were uploaded to NVivo 11 and analysed using thematic analysis.

\section{Results}

Barriers and facilitators were related to work, stigma, and symptoms. Specifically, GPs discussed feeling a need to attend work, the stigma surrounding mental ill health, and issues around time, confidentiality, and privacy. Participants also reported difficulties accessing good-quality treatment. GPs also talked about cutting down or varying work content, or asserting boundaries to protect themselves.

\section{Conclusion}

Systemic changes, such as further information about specialist services designed to help GPs, are needed to support individual GPs and protect the profession from further damage.

\section{Keywords}

anxiety; burnout, professional; depression; general practice; mental health services; selfcare.

\section{INTRODUCTION}

GPs are operating under significant workload pressures and with diminishing resources. ${ }^{1,2}$ Funding has been cut for primary care while expenses have risen. ${ }^{3}$ Workload for GPs has increased by $16 \%$ in the past 7 years, ${ }^{4}$ while less than one in five UK Foundation Year 2 doctors went into general practice in $2015 .^{5}$ The patient population is growing faster than the GP workforce, with rising demands due to an ageing population and increase in multimorbidity.6,7 Additional pressures for GPs in the UK come from sources such as the Quality and Outcomes Framework (QOF) and the implications of future cuts in NHS funding. ${ }^{6}$

Reports of GPs feeling dissatisfied, distressed, anxious, ${ }^{7,8}$ and suicidal $^{9}$ are rising. Some GPs report misuse of substances, ${ }^{7}$ while others feel exhausted, 'grumpy', and have feelings of hatred towards their work. ${ }^{10}$ It has been suggested that personality traits such as perfectionism and workaholism, with which many GPs may identify, can contribute to anxiety, depression, and eating disorders for physicians. ${ }^{7}$ Additionally, several authors cite concerns for patient safety as a result of GP

J Spiers, PhD, formerly senior research associate Centre for Academic Primary Care; D Kessler MD, MRCGP, MRCPsych, reader in primary care Centre for Academic Primary Care; $\mathbf{N}$ Leggett

MA, patient and public contributor, Centre for Academic Primary Care; AK Taylor; MBChB, medical student, Faculty of Health Sciences; G Thornton, MRes, patient and public contributor Centre for Academic Primary Care, University of Bristol, Bristol. M Buszewicz, MRCGP, MRCPsych, reader in primary care, Research Department of Primary Care and Population Health, UCL, London. CA Chew-Graham, MD, FRCGP, professor of general practice research, Research Institute, Primary Care and Health Sciences, Keele University, Keele, Staffordshire. C Gerada, MBE, FRCP, FRCGP, MRCPsych, medical director Practitioner Health Programme, Riverside Medical Centre, London. C Manning. MRCGP, DRCOG distress. ${ }^{8}$ Low levels of personally reported physician individual accomplishment have correlated with emotional exhaustion and depersonalisation, ${ }^{11}$ and high levels of pressure may lead to decision fatigue. ${ }^{3}$ However, findings have shown that patients ratings do not reflect GPs' sense of being burnt out; patients rate 'burnt out' GPs as highly as healthy GPs. This suggests that unwell GPs continue to deliver a high standard of care, and maintain a balance between emotional contagion and professionalism, even if they do not feel that this is the case. It may also be that burnt-out GPs become skilled at hiding their feelings.

Despite this negative picture, it may be noted that one GP in a qualitative study reported the extra pressure as a benefit as it can result in more strategic thinking. ${ }^{6}$ In addition, emotional labour such as that faced by GPs on the frontline has been found to be valued over other aspects of work, and may lead to increased job satisfaction. ${ }^{12}$

GPs may lack support, ${ }^{13}$ and there are barriers to help-seeking for distressed doctors, such as concerns about confidentiality, ${ }^{7}$ presenteeism lattendance at work despite ill health), ${ }^{7}$ long working

director, Upstream Health Convener, Action for NHS Wellbeing Chair Mental Health Group, College of Medicine, London. R Riley, PhD, lecturer in applied health research, Institute of Applied Health Research, College of Medical and Dental Sciences, University of Birmingham, Birmingham Address for correspondence

Johanna Spiers, 2 The Old Byre, East Dundry Lane, East Dundry, Bristol BS41 8NH, UK.

E-mail: Johanna.Spiersdgmail.com Submitted: 10 April 2017; Editor's response: 16 May 2017; final acceptance: 13 July 2017. (c)British Journal of General Practice This is the full-length article (published online 12 Sep 2017) of an abridged version published in print. Cite this version as: $\mathbf{B r} \mathbf{J}$ Gen Pract 2017; DOI: https://doi.org/10.3399/bjgp17X692573 


\section{How this fits in}

It is known that GPs are currently working in an environment of rising pressures and diminishing resources. Their satisfaction with their work is lessening, while stress levels rise, and GPs may have difficulty seeking help when they are experiencing mental distress. This study makes explicit the barriers and facilitators that face GPs as they consider seeking treatment for mental illness, as well as exploring the ways in which they may protect themselves from their workplace stresses.

hours, and stigma around mental illness. ${ }^{14,15}$ Research about ways of lessening the distress experienced has tended to explore short-term interventions geared towards increasing resilience. ${ }^{16,17}$ In addition, much previous work has focused on the impact of physician wellbeing on patient outcomes, meaning the emphasis is not on the needs of GPs themselves. $8,18,19$

The concept of resilience is problematic, as it places the responsibility for managing pressure with the individual, rather than the organisation, ${ }^{20}$ and there is a need for research into health practitioner wellbeing, in order to value that wellbeing for its own sake.

This study aimed to explore the barriers and facilitators to help-seeking for GPs living with distress.

\section{Box 1. Topic guide}

\section{Current wellbeing}

- Describe average working day in practice (hours, surgery, and home visits) and any additional responsibilities

- Explore current wellbeing, feelings about work, levels of stress, work-life balance

- Explore causes of stress/distress (workload, hours, admin, clinical caseloads, organisational issues, lack of support, personal issues, and pre-existing mental health symptoms)

- Explore reasons for early retirement/sickness (if relevant)

\section{Managing stress}

- Explore how GPs manage their workload/stress in their day-to-day work life, what they do to relax, to look after themselves (self-care strategies: supportive relationships, sport, exercise, and relaxation techniques)

- Explore relationship with colleagues and whether/how/if concerns are raised, how they are responded to

- Explore if receive informal/formal supervision or mentor (one to one or group) and experience/value of group

- Explore thoughts/feelings about seeking help, barriers to seeking help /stigma/shame, fears about confidentiality, and uncertainty of where to gol

\section{Experience of help-seeking (where relevant)}

- Explore experience of help-seeking for reduced wellbeing and/or mental health symptoms (friends, colleagues, family, GP, specialist service [Practitioner Health Programme], mental health professional, counsellor, and therapist)

- If primarily of specialist service, explore how heard of service, contacted them, their experience of service,

feelings about seeking help, what support offered

- Explore what helped/how benefited from the service

- Explore suggestions for improving the service/anything done differently

- Any difficulties accessing the service

\section{Any other issues}

- Any other issues the participant would like to raise

\section{METHOD}

Given the study's focus on the experience of GPs, a qualitative approach was used. Existing qualitative work has tended to use smaller samples. ${ }^{6,21,22}$ or examine the experiences of GPs in different parts of the world. ${ }^{17}$ The study aimed to address these limitations by eliciting a larger group of English GPs' feelings concerning what helps and hinders them in receiving support for their chronic stress or distress, hence giving greater weight to the intrinsic, rather than extrinsic, value of GP wellbeing.

Interviews with 47 GPs from around England were conducted. Potential participants were contacted via e-mail to doctors attending a specialist service, as well as adverts to local medical committees (LMCs) nationally, in GP publications, and on social media. A total of 122 GPs got in touch, although 18 of these did not send a second response after receiving an information sheet.

Potential participants were asked which of these categories they most strongly identified with:

- living with mental distress /defined as anxiety, depression, stress, and/or burnout);

- returning to work following treatment for such problems;

- off sick or retired early because of mental distress; or

- no lived experience of mental distress.

Interested GPs were purposively sampled to represent a relatively even spread across these four groups, although the largest number of participants were in Group 1. Once each group was well represented, further GPs who expressed an interest in participation were politely thanked and turned away. The authors intended to purposively sample approximately 10 participants per group. However, the majority of GPs who contacted the authors self-selected into Group 1 and, due to the emergent rich data, continued recruitment to this group was considered justified. The authors endeavoured to recruit more participants into Groups 2 and 4 using targeted publicity information, but due to time constraints those groups remained marginally under-recruited. In the event, many GPs who identified as living with no stress reported having had experiences of work-related stress and distress at some juncture in their career.

Data collection took place face to face or by telephone, between February and August 2016. Semi-structured interviews 
consisted of questions exploring wellbeing, stress management, and help-seeking, as shown in the topic guide (Box 1). The analysis process began while interviewing was ongoing. The interview schedule was updated based on early analysis to include additional questions on topics, including the impact of distress on practice and the impact of early retirement on finances. Interviews lasted between 27 and 126 minutes (mean $=69$ minutes), and were recorded and transcribed verbatim.

Transcripts were uploaded to NVivo 11 and analysed using thematic analysis. ${ }^{23}$ Each transcript led to emergent codes being added to and refined. Emerging themes were discussed and agreed among all authors. A code book of key points from all interviews was drawn up. This was audited by two of the authors, both experienced qualitative researchers. The multidisciplinary research team independently analysed a subset of transcripts, contributing to the refinement of codes, and maximising rigour. Emergent themes were discussed by the whole team.

Tables of themes were drawn up for the major codes. Analysis continued into the writing process, when adjustments

\section{Table 1. Participant demographics}

\begin{tabular}{|c|c|}
\hline Sex (female) & $47(33)$ \\
\hline \multicolumn{2}{|l|}{ Age, years } \\
\hline $20-29$ & 1 \\
\hline $30-39$ & 12 \\
\hline $40-49$ & 20 \\
\hline $50-59$ & 14 \\
\hline \multicolumn{2}{|l|}{ Group } \\
\hline 1 & 19 \\
\hline 2 & 9 \\
\hline 3 & 11 \\
\hline 4 & 8 \\
\hline \multicolumn{2}{|l|}{ Years since qualified } \\
\hline$<10$ & 19 \\
\hline \multicolumn{2}{|l|}{ Number of sessions contracted per week } \\
\hline$<5$ sessions (mean actual hours worked) & $12(15)$ \\
\hline$>5$ sessions (mean actual hours worked) & 32 (38) \\
\hline Fully retired & 3 \\
\hline Mean size of practice & 12624 \\
\hline Range & $3600-37000$ \\
\hline \multicolumn{2}{|l|}{ Employment status } \\
\hline Partner & 17 \\
\hline Salaried & 11 \\
\hline Locum & 5 \\
\hline Registrar & 4 \\
\hline Retired & 3 \\
\hline Sick leave & 5 \\
\hline More than one role & 2 \\
\hline
\end{tabular}

were made to ensure that each theme was explored optimally.

\section{RESULTS}

A total of 122 GPs responded to recruitment advertisements, of whom 47 were purposively selected to ensure a relatively even split across the four groups mentioned before. Participant demographics are shown in Table 1.

Findings were identified across all groups, including Group 4, who had identified as having no mental health concerns. The themes also applied to participants irrespective of seniority/role in the practice, age, and sex.

Data were divided into two main themes and corresponding sub-themes:

- barriers and facilitators to help-seeking for distress - work related, symptom related, and access to support; and

- survival strategies - cutting down or varying workload, and asserting boundaries.

\section{Barriers and facilitators to help-seeking \\ for distress}

Work-related barriers and facilitators. a) The need to attend work: participants talked about a perceived need to go to work, even when unwell, as a barrier to seeking support. Such 'presenteeism' was compounded by workforce shortages and difficulty accessing locum cover, in addition to guilt at letting down patients and colleagues:

I fought and fought and fought not to go off sick, because the guilt associated with going off sick is so huge. [...] Everybody's struggling, so if I go off sick I will just make everybody else struggle even more. But it got to the point where it was making me quite ill.' (P24, female, partner)

If you don't go in, no one else covers you. [...] And your workload doesn't disappear, so whoever is there has to take it on.' (P3, female, salaried)

b) Stigma associated with mental illness: mental illness is stigmatised. Several participants perceived that there was a specific stigma attached to being a GP experiencing such ill health:

'There is a sort of an unwritten rule that you don't admit to mental illness in any way in general practice, I think. Even though everybody knows that everybody has it, it's 
just not talked about.' (P9, male, partner)

For others, stigma was internalised, meaning illness itself was framed as failure:

'You're not groomed to be ill, are you? You're not groomed to be a failure.' (P36, male, partnerl

The perceived stigmatising attitudes of colleagues to patients with mental illness may also work as a barrier to help-seeking:

It was about all the voices I've heard from GPs saying, you know: "They just need to pull themselves together." Or, you know: "All they ever want is pills."' (P20, male, partner)

In contrast, participants discussed how openness around distress could ease helpseeking:

I have got a colleague here with mental health problems. And I have to say, she's fantastic. She's absolutely brilliant about telling you how she is, how she's feeling, medication she's taking. And that degree of openness is really refreshing.' (P22, male, salaried)

Participants also took the opportunity to combat stigma by speaking out to colleagues and patients about the realities of GP distress and experience:

I try and act as a bit of an advocate, really, within the practice, and within medical circles. I haven't - I haven't hidden any of it.' (P24, female, partner)

All the stuff in the papers [...] definitely feels quite demoralising. When we talk about it in our VTS [vocational training scheme] group we're just like: "Yeah, because we're rubbish and we're overpaid." [...] If patients come in and say something like that, I will - you know, something like: "I've been reading this in the Daily Mail" - will, where I am able, refute it and explain [pause] the alternative viewpoint.' (P43, female on sick leave)

c) Confidentiality, time, and identity: privacy and confidentiality were cited as impediments to help-seeking. Many feared their patients might find out about their mental health concerns:

If you went to like a counselling group, you'd be worried you'd bump into one of your patients.' (P26, female, salaried)
Also prevalent were concerns around the impact of relationships with colleagues on confidentiality:

I knew all these GPs in [location], and it was a close-knit community. And, suddenly, all my colleagues that were training to be GPS were training in all the different practices in [location], which potentially had - could have - wherever I was registered would have access to my notes and know exactly what was going on with me. (P5, female, locum and salaried)

Participants found lack of time to be an impediment to both help-seeking and self-care:

Never mind reflective practice and Balint groups and all of this, people are just, you know, nose to the grindstone absolutely all of the time.' (P7, female, locum)

GPs talked about the difficulty of moving between doctor and patient identity to accept help:

'Whether it's being a doctor as a patient that's difficult, or the fact that you're being a patient and seeing the room from, you know, a very familiar situation from another viewpoint.' (P47, female on sick leave)

Symptom-related barriers and facilitators. Acknowledging that they had a mental health problem was difficult for many participants:

'The hardest thing is to acknowledge that you've got a problem.' (P30, female, salaried)

Inertia resulting from depression could also act as a barrier:

If you're that exhausted you can't see a way out, because to try and see a way out requires some effort.' (P29, female, partner)

However, for some participants, reaching crisis point spurred them into action:

'The trigger for me was that I could not stop thinking that I wanted to kill myself.' (P20, male, partner)

'I think I just had to be ill enough. I didn't realise how ill I was until I was off work, and then it became quite clear to me I was seriously quite unwell and needed, you know, I needed to do something fairly serious.' (P36, male, partner) 
Access to support. a) Quality of treatment: participants reported a perceived inadequacy of psychological treatments as a difficulty when they were seeking effective help. One GP reported an inadequate response despite her suicidal feelings:

I saw her for the first couple of sessions, and then she said: "Oh, I can't see you for another 2 weeks." And I was quite suicidal at the time.' (P4, female on sick leave)

One found that his status as a GP appeared to negatively impact the quality of help he received:

She [GP] said: "Well, what do you do?" "I'm a GP." "Well, we're all stressed, aren't we?" was the answer.' (P45, male, salaried)

A good relationship with one's own GP helped secure effective treatment:

I feel that I've been very lucky that both the GPS who l've seen over this problem have been very understanding and sympathetic. (P28, male on sick leave)

b) Accessing information about relevant resources: some participants felt unsure of where to turn if they decided to seek help:

I did a burnout score around that time, on the RCGP website, and it said: "Oh, you're at risk of burnout." And then it had no suggestions of what to do.' (P46, female, partner)

However, one GP gave an example of best practice. Her surgery disseminated helpful information about services for GPs:

My practice has just recently produced a document, like an A4 document, with online help for GPs and the local support agencies. So they've just laminated that, and they're just putting it in the doctors' runs. [...] / think probably having something there and a number makes it a bit more accessible. (P3, female, salaried)

c) The availability of a specialist, confidential service: participants talked enthusiastically about the benefits of going to a specialist, confidential treatment facility:

'People who are treating doctors need to treat them like patients. That is a very skilled job. Because it's so easy to collude, it's so easy to see your stuff in them. It's an incredibly hard job to do well. And so it needs to be specialised.' (P31, female, locum)
As a doctor you can cover it up for a lot longer till you're in a much worse state, and [pause] you need experienced people that are not going to be flannelled by that. And if you go to your GP, you've only got a 10-minute appointment, and I can pretend I'm fine in a 10-minute appointment, but I couldn't for an hour and a half.' (P43, female on sick leave

The confidential nature of specialised services was of importance:

'The LMC thing was completely confidential; it was outside of the area so I thought that was fine, so that seemed to make sense. (P27, female, partner)

Most users of specialised services spoke of them highly:

I just thought was really fantastic because - they're used to having doctors. And they take everything seriously. They've got time to kind of go through things.' (P48, female, registrar)

However, a small number had reservations:

If I were to have what I thought was a sexually transmitted infection, I'd probably go to my GP rather than go to the sexual health centre. Because, if I'm going to the sexual health centre, everyone will think: "She's got an STI." Whereas if I go to my GP I can get exactly the same service. [...] If I went I'd bump into colleagues and it might be a bit awkward because we'd all know that we were there for the same reason. (P3, female, salaried)

d) The influence of work environment on access to support: an unsupportive environment at work could impede selfcare:

My role as senior partner, oddly enough, had been just to sort of keep my head down and keep going. So if anything happened to me, it sort of destabilises them and then they would react very badly to the fact that I was off.' (P49, female, retired)

However, participants reported emotional support from colleagues as helpful:

'One of my colleagues came in and said: "You've got to phone someone." I'll never forget that, you know, she insisted. I'd been talking about it for weeks to my wife and to colleagues here. And she came in and 
said: "You'd better do something." And she'd probably seen something in the way / was that I hadn't seen myself.' (P19, male, partner)

\section{Practical support was also reported:}

I'd said how stressful l'd been to these two female partners of mine, and we'd had a meeting and talked about it. And they tried to find some ways of helping. I said things like, it would be nice, if I get lots of extras, if someone from the staff could make a cup of tea?' (P35, female, retired)

\section{Survival strategies}

Participants discussed a wide range of survival strategies, many of which have been documented extensively elsewhere. ${ }^{6,24-26}$ Due to this existing extensive literature, the authors made the decision to focus on those strategies that are less widely reported, or that have particular relevance for GPs within this article.

Cutting down orvarying work content. Some participants had resigned or retired due to distress:

I'm just thoroughly enjoying myself. I've never had time to myself in my life. So I'm seeing friends, I'm going for runs, I'm walking the dog, I'm interested in cooking and, yeah, for the first time in my life I'm actually relaxed and happy.' (P49, female, retired)

However, others considered resigning as a possible last resort:

'I really don't want to go. But if things get worse, I would go.' (P30, female, salaried)

Participants often felt that working fewer sessions was necessary to stay healthy:

I've actually always worked part time since I've been a GP. And I think that is the essence of good mental health. I don't think people should be allowed [laughs] to work full time really.' (P1, female, partner)

Lessening workload could mean working as a locum, which some perceived as offering additional control:

'You pretty much don't get any admin, so it's all just see patients, go home on time.'(P26, female, salaried)

Participants talked about planning for longer consultations with patients than the standard 10 minutes, a strategy designed to make the day less stressful:
'Patients booked in at 15-minute intervals. Which is bliss.' (P35, female, retired)

Participants sometimes restructured their working lives to maintain good mental health. For many, this involved cultivating a portfolio career. Other roles taken on included training, committee work, and consultancy:

I worked at the Sally Army helping the homeless with drug problems. [...] And that was nice, because a day a week I was doing that. [...] If you still want to work 4 or 5 days a week, you can. But if for one or two of those days you're not doing just GP-ing, it's a break.'(P37, female on sick leave)

Asserting boundaries. The importance of saying no to extra work was emphasised by GPs, either for themselves or colleagues:

'Establishing boundaries, understanding what your limitations are, you know, saying no, just not for the sake of saying no, but learning to say no and don't feel guilty.' (P41, female, locum)

So I think really that in a partnership you should acknowledge that and actually say no to people that want to take on what's obviously too much.' (P1, female, partner)

Boundaries could be established by finding ways to cut down hours or roles:

We have started being a training practice deliberately to kind of, take the pressure off us a little bit.' (P17, female, partner)

Participants also talked about knowing when to stop work:

I never put the computer back on when I go home.' (P46, female, partner)

I'll say: "I'm doing that tomorrow." Because, it's 7 o'clock and I want to see my children before they go to bed.' (P18, male, partner)

\section{DISCUSSION}

\section{Summary}

This study reports barriers and facilitators to help-seeking for GPs living with mental ill health and/or chronic stress. Workload barriers included guilt-induced presenteeism, internalised and perceived stigma, and concerns about privacy and confidentiality. A lack of time and inability to move between doctor and patient identities also made help-seeking challenging. Distressed GPs often found it difficult to 
overcome their feelings of inertia or did not always acknowledge their own illness to themselves. In contrast, some GPs found that reaching crisis point spurred them on to seek help. A lack of access to adequate treatment was reported by many, although confidential services for practitioners were reported to be useful by others. Some striking examples of openness around mental ill health between colleagues were also given, and these had clearly worked to facilitate getting support or access to professional help. Findings around potential survival strategies, including cutting down or varying workload, and asserting boundaries were also reported.

\section{Strengths and limitations}

This research is timely, focusing as it does on the GP experience of distress, and adds to a growing cohort of recent studies concerned with this topic. ${ }^{6.7}$ This research provides insights into GPs' perspectives of barriers and facilitators to help-seeking. The authors interviewed a range of GPs from different geographical areas and in different roles (that is, partners, salaried, or locums), offering a balanced view of GPs in need of effective support.

A potential limitation is that the sample was self-selected, meaning the authors spoke to GPs who felt able to communicate with them. It may be that the most vulnerable GPs were too distressed to respond to advertisements or feel able to talk. However, given the large number of GPs who got in touch, and the range of views expressed, it is hoped that the authors spoke to a representative sample.

\section{Comparison with existing literature}

Continued attendance at work while unwell has been reported previously, 7,14,27,28 and it has been suggested that this lack of self-care may result in longer periods of time off sick further down the line. ${ }^{29}$ These findings add depth to this information around 'presenteeism', by showing the degree of guilt associated with the pressure to stay at work that can drive this unhealthy practice. Participants also confirm the continued perceived stigma around mental illness. ${ }^{14,15,30}$ The findings suggest this may be a particular problem for those working in general practice.

Existing work highlights the difficulty in acknowledging symptoms of mental ill health, ${ }^{31}$ and denial or avoidance, ${ }^{7}$ as barriers to help-seeking among clinicians in general. Some GPs in this study who recognised the importance of their symptoms were, however, prompted by this to seek help. Given the high rates of suicide among doctors in general and GPs in particular,? it is imperative that UK GPs are given the support they need so that they can access appropriate help before they reach this crisis point.

Treatment for doctors in distress can be inadequate. ${ }^{32-35}$ The positive value of a good relationship with a GP was emphasised, while participants also confirmed the importance of offering specialist services for doctors. ${ }^{27,35}$ A particular feature of specialist services is that they emphasise confidentiality and are available outside usual local care, hence minimising the aforementioned barrier of concerns around privacy. It is hoped that the new NHS GP Health Service ${ }^{36}$ will provide an accessible, specialised service for GPs.

It is noteworthy that some participants highlighted the emotional and practical support they had received within their practice as facilitators to help-seeking, although this was by no means universal, with some practices being perceived as very unsupportive environments. The proactive examples of good practice at work cited by the participants are encouraging, and demonstrate the importance of supportive partnerships. The need for doctors to develop good teamwork strategies has previously been emphasised, ${ }^{37}$ and these findings also support this recommendation.

Participants discussed a wide range of potential survival strategies, some of which have been cited elsewhere, such as exercise, ${ }^{25,26}$ mindfulness, and meditation, ${ }^{38}$ and support groups such as Balint groups. ${ }^{24,39}$ A recent article found that many GPs have reduced their sessions in order to cope with the stress of an increasing workload. ${ }^{22}$ These findings build on this by adding detail to the ways in which GPs might vary their working days or assert their boundaries, demonstrating ways in which individual GPs may protect themselves within the current general practice structure. However, while these may be beneficial strategies for the individual, they could have damaging consequences for patients and the profession unless there are resources available to recruit more GPs.

\section{Implications for research and practice}

The findings demonstrate the concerning extent of the crisis point that some GPs reach before they seek help for stress-related or mental health difficulties. There needs to be a cultural shift within the medical profession and the NHS, so that the ongoing stigma of mental illness is confronted, making it easier for GPs to recognise and 
speak out about their difficulties before they reach such a crisis. One systematic review has argued that systemic barriers to help-seeking are more important - and more difficult to overcome - than individual ones. ${ }^{33}$ The authors agree, and recommend that systemic stigma around mental ill health within healthcare organisations is a key area needing to be addressed by researchers and policymakers.

In line with these findings, previous authors have reported that doctors and medical students often do not know about existing specialist mental health services. ${ }^{27,30}$ The authors recommend that individual practices, the RCGP, deaneries, clinical commissioning groups, LMCs, and the Department of Health do more to advertise these services, such as the new NHS GP Health Service. The authors also suggest that GPs are offered specific training about how to effectively support and treat their GP and other medical colleagues when they attend as patients, because effective primary care may be an essential lifeline for doctors in distress.

Finally, the authors recommend that researchers and policymakers respond to research such as theirs and others, ${ }^{6,7}$ as well as the General Practice Forward View, ${ }^{40}$ by investigating and developing organisational changes that will enable the workload stresses experienced by GPs to become more manageable for individuals, $22,41,42$ while ensuring sufficient resource and practitioners for the delivery of good medical care for all. These strategies must emphasise both the mental and physical health of GPs by putting in place measures both to prevent distress and provide support should it arise, so that the profession may continue to thrive and grow.

\section{Funding}

The study was funded by the National Institute for Health Research (NIHR) School for Primary Care Research Ireference number 282).

\section{Ethical approval}

Ethical approval was granted by the South West - Frenchay Research Ethics Committee (reference number: 15/SW/0350).

\section{Provenance}

Freely submitted; externally peer reviewed.

\section{Competing interests}

One author, Clare Gerada, is medical director at GP Health Service. The remaining authors declare no competing interests.

\section{Acknowledgements}

The authors would like to thank all volunteer participants who kindly gave their time to share their experiences of working in English general practice. The views and opinions expressed are those of the authors and do not necessarily reflect those of the NIHR School for Primary Care Research, the NIHR, the NHS, or the Department of Health.

\section{Discuss this article}

Contribute and read comments about this article: bjgp.org/letters 


\section{REFERENCES}

1. Majeed A. Primary care: a fading jewel in the NHS crown. London J Prim Care 2015; 7(5): 89-91.

2. Checkland $\mathrm{K}$, Spooner $\mathrm{S}$. The future of primary care? Reflections on the Primary Care Workforce Commission report. Br J Gen Pract 2015; DOI: https://doi.org/10.3399/bjgp15X686773

3. Baird B, Charles A, Honeyman $\mathrm{M}$, et al. Understanding pressures in general practice. London: King's Fund, 2016.

4. Hobbs FDR, Bankhead C, Mukhtar T, et al. Clinical workload in UK primary care: a retrospective analysis of 100 million consultations in England, 2007-14. Lancet 2016; 387(10035): 2323-2330.

5. McDonald P, Jackson B, Alberti H, Rosenthal J. How can medical schools encourage students to choose general practice as a career? Br J Gen Pract 2016; DOI: https://doi.org/110.3399/bjgp16X685297.

6. Croxson CHD, Ashdown HF, Hobbs RFD. GPs perceptions of workload in England: a qualitative interview study. Br J Gen Pract 2017; DOI: https://doi. org/10.3399/bjgp17X688849.

7. Wallace J, Lemaire J, Ghali W. Physician wellness: a missing quality indicator. Lancet 2009; 374(9702): 1714-1721.

8. Murray M, Murray L, Donnelly M. Systematic review of interventions to improve the psychological well-being of general practitioners. BMC Fam Pract 2016; 17(1): 36.

9. Braquehais MD, Eiroa-Orosa FJ, Holmes KM, et al. Differences in physicians and nurses' recent suicide attempts: an exploratory study. Arch Suicide Res 2016; 20(2): 273-279.

10. Doran N, Fox F, Rodham K, et al. Lost to the NHS: a mixed methods study of why GPs leave practice early in England. Br J Gen Pract 2016; DOI: https://doi. org/ 10.3399/bjgp16X683425..

11. Orton P, Orton C, Pereira Gray D. Depersonalised doctors: a cross-sectional study of 564 doctors, 760 consultations and 1876 patient reports in UK general practice. BMJ Open 2011; 1: e000274.

12. Riley $\mathrm{R}$, Weiss MC. A qualitative thematic review: emotional labour in healthcare settings. JAdv Nurs 2016; 72(1): 6-17.

13. Spiers J, Buszewicz M, Chew-Graham $C$, et al. Who cares for the clinicians? The mental health crisis in the GP workforce. Br J Gen Pract 2016; DOI: https://doi.org/10.3399/bjgp16X685765

14. Garelick Al. Doctors' health: stigma and the professional discomfort in seeking help. Psychiatrist 2012; 36(3): 81-84

15. Fox FE, Doran NJ, Rodham KJ, et al. Junior doctors' experiences of personal illness: a qualitative study. Med Educ 2011; 45(12): 1251-1261.

16. Sood A, Prasad K, Schroeder D, Varkey P. Stress management and resilience training among Department of Medicine faculty: a pilot randomized clinical trial. J Gen Intern Med 2011; 26(8): 858-861.

17. Stevenson AD, Phillips CB, Anderson KJ. Resilience among doctors who work in challenging areas: a qualitative study. Br J Gen Pract 2011; DOI: https://doi. org/10.3399/bjgp11X583182

18. Brimstone R, Thistlethwaite JE, Quirk F. Behaviour of medical students in seeking mental and physical health care: exploration and comparison with psychology students. Med Educ 2007; 41(1): 74-83.

19. Chen JY, Tse EY, Lam TP, et al. Doctors' personal health care choices: a crosssectional survey in a mixed public/private setting. BMC Public Health 2008; 8(1) 183.

20. Balme E, Gerada C, Page L. Doctors need to be supported, not trained in resilience. BMJ Careers 2015; http://careers.bmj.com/careers/advice/Doctors need_to_be_supported,_not_trained_in_resilience laccessed 11 Aug 2017).
21. Fox FE, Harris M, Taylor G, et al. What happens when doctors are patients? Qualitative study of GPs. Br J Gen Pract 2009; DOI: https://doi.org/10.3399/ bjgp09X472872.

22. Fisher RFR, Croxson CHD, Ashdown HF, Hobbs FDR. GP views on strategies to cope with increasing workload: a qualitative interview study. Br J Gen Pract 2017; DOI: https://doi.org/10.3399/bjgp17X688861.

23. Braun V, Clarke V. Using thematic analysis in psychology. Qual Res Psychol 2006; 3(2): 77-101

24. Gunasingam N, Burns K, Edwards J, et al. Reducing stress and burnout in junior doctors: the impact of debriefing sessions. Postgrad Med J 2015 91(1074): 182-187

25. Zwack J, Schweitzer J. If every fifth physician is affected by burnout, what about the other four? Resilience strategies of experienced physicians. Acad Med 2013 88(3): 382-389.

26. Aase M, Nordrehaug JE, Malterud K. 'If you cannot tolerate that risk, you should never become a physician': a qualitative study about existential experiences among physicians. J Med Ethics 2008; 34(11): 767-771.

27. Brooks SK, Gerada C, Chalder M. Review of literature on the mental health of doctors: are specialist services needed? J Ment Health 2011; 20(2): 146-156.

28. Oxtoby K. Why doctors need to resist 'presenteeism'. BMJ 2015; 351: h6720.

29. Conchar C, Repper J. 'Walking wounded or wounded healer?' Does personal experience of mental health problems help or hinder mental health practice? A review of the literature. Mental Health Soc Incl 2014; 18(1): 35-44.

30. Chew-Graham CA, Rogers A, Yassin N. 'I wouldn't want it on my CV or their records': medical students' experiences of help-seeking for mental health problems. Med Educ 2003; 37(10): 873-880.

31. Gold KJ, Andrew LB, Goldman EB, Schwenk TL. 'I would never want to have mental health diagnosis on my record': a survey of female physicians on mental health diagnosis, treatment, and reporting. Gen Hosp Psychiatry 2016; 43: 51-57.

32. Davidson S, Schattner P. Doctors' health-seeking behaviour: a questionnaire survey. Med J Aust 2003; 179(6): 302-305.

33. Kay M, Mitchell G, Clavarino A, Doust J. Doctors as patients: a systematic review of doctors' health access and the barriers they experience. $\mathrm{Br} J \mathrm{Gen}$ Pract 2008; DOI: https://doi.org/10.3399/bjgp08X319486.

34. Kay M, Mitchell G, Clavarino A, Frank E. Developing a framework for understanding doctors' health access: a qualitative study of Australian GPs. Aust J Prim Health 2012; 18(2): 158-165.

35. Brooks SK, Gerada C. Chalder T. The specific needs of doctors with mental health problems: qualitative analysis of doctor-patients' experiences with the Practitioner Health Programme. J Ment Health 2017; 26(2): 161-166.

36. NHS England. NHS GP Health Service. 2017. https://uww.england.nhs.uk/gp/ gpfv/workforce/health-service/ laccessed 11 Aug 2017).

37. Garelick A, Fagin L. Doctor to doctor: getting on with colleagues. Adv Psychiatr Treat 2004; 10: 225-232.

38. Fortney L, Luchterhand C, Zakletskaia L, et al. Abbreviated mindfulness intervention for job satisfaction, quality of life, and compassion in primary care clinicians: a pilot study. Ann Fam Med 2013; 11(5): 412-420.

39. Taubert M, Nelson A. Heartsink encounters: a qualitative study of end-of-life care in out-of-hours general practice. JRSM Short Rep 2011; 2(9): 70.

40. NHS England. General practice forward view. 2016. https://www.england.nhs. uk/wp-content/uploads/2016/04/gpfv.pdf laccessed 11 Aug 2016).

41. Orri M, Revah-Lévy A, Farges O. Surgeons' emotional experience of their everyday practice - a qualitative study. PLoS One 2015; 10(11): e0143763.

42. Montgomery A. The inevitability of physician burnout: implications for interventions. Burn Res 2014: 1(1): 50-56. 